\title{
Governance and Economic Convergence in the Mediterranean Arab Countries
}

\author{
Najah Souissi ${ }^{1}$ \\ ${ }^{1}$ Faculty of Economic Sciences and Management of Tunis, Tunisia \\ Correspondance: Najah Souissi, 7 street Wahrane 2040 Rades Méliène Tunis, Tunisia. Tel: 216-2060-6547. \\ E-mail: najah_souissi@yahoo.fr
}

Received: September 11, 2013

Accepted: October 28, $2013 \quad$ Online Published: December 23, 2013

doi:10.5539/ijef.v6n1p66

URL: http://dx.doi.org/10.5539/ijef.v6n1p66

\begin{abstract}
In this article, we propose an endogenous growth model with technological diffusion and rent seeking activity. We show that, the diffusion of technology from north to south countries depends on the existence of a "social capability" and in particular of a favourable institutional environment in the host countries. Moreover, we show that the gaps in product per capita between countries can't be resorbed due to deficient institutions in the southern economies. In fact, the prevailing culture of governance in these economies is characterized by a locked social order and a state capture by political and economic elites, such institutional environment reduces the incentive of individuals to invest and to adopt new technologies.

Furthermore, we accomplish an empirical validation of these results. We consider a panel of Mediterranean Arab Countries during the period 2000-2010 and we apply the instrumental variables method. We show that, the results are consistent with the theoretical model; a system of governance characterized by a strong collusion between economic and political elites inhibits convergence of GDP per capita between economies.Our contribution in this paper includes also the construction of a composite index that measures the degree of openness of the insider system in an economy.
\end{abstract}

Keywords: governance, rent seeking, economic growth, technology transfer

\section{Introduction}

Many theoretical and empirical studies initiated by Abramovitz (1986), Stern (1991), Hansson and Henrekson (1997), Barett (1997), Keefer and Knack $(1995 ; 1997)$ and extended by others maintained that technological catching-up of poor economies depends on the availability of a sufficient degree of "social capability", that is, the poorer countries must be sufficiently sophisticated in order to be able to assimilate the more advanced technology.

According to Hansson and Henrekson (1997), this "social capability" is determined by the level of education of the population, the degree of organization of firms, the degree of integration into the international economy, the degree of competition in domestic markets, the managerial competence, how clearly property rights are defined and the quality of infrastructure including features of social infrastructure such as honesty and benevolence of the bureaucracy.

In this work we focus our interest on the political and institutional dimension and we show that the existence of a "social capability" materialized by a favorable institutional environment is a necessary condition for a retarded economy to absorb foreign technology and converge to GDP/capita of advanced economies.

According to OuelAoudia (2006), OueldAoudia and Meisel (2008), Meisel (2004), Nabli, Silva and Aysan(2008), El Morched (2008),Gobe (2007), Catusse (2009), Souissi (2013) the institutional system prevailing in most developing economies, in particular in the Mediterranean Arab countries, is an obstacle to their economic takeoff and their convergence to advanced economies. In fact, the prevailing culture of governance in these economies is characterized by a locked social order and a strong collusion between economic and political elites that provide "broadly inclusive" interest (encompassing) in the rents generated by the economy. The power is articulated around the couple allegiance / fidelity, on the one hand and privileges / advantages, on the other hand.

The public choice theory initiated by Tullock (1967) and then extended by Stigler (1971), Peltzman (1976), Tollisson (1982), Buchanan (1980), Muller (1989) and others show how the public sector operate effectively and 
contest the vision of the State "benevolent despot" as well as provide the public sector actors, policy makers and bureaucracy, own individual goals. To the extent that the State has a monopoly on production of the "rule of law", through which he defines property rights, the State is then presented as the most powerful generators of transfers. To capture such transfers, individuals are organized into interest groups and allocate time and resources to try to benefit.

In this regard, Olson (1982) shows that the collusion between private interests and the omnipresence of rent-seeking activity in an economy inhibit any economic progress and make uphandicaps on technological diffusion and the reduction of the Product per capita gap between economies. The proliferation of coalitions of private interests in an economy create barriers to entry to profitable sectors and generate a slower reallocation of resources to more productive sectors and thus a reduction in the overall productivity of the economy. Similarly, the omnipresence of coalitions of private interests creates a conflict and political uncertainty in economic policy. This creates uncertainty about protecting private property rights and will tend to reduce the levels of investment and production.

Furthermore, Parente and Prescott (1999) show that the distribution of monopoly rights to particular interest groups reduce the individual's incentive to adopt a new technology. In fact, special interest groups can monopolize the present and the potential process of production and establish barriers to entry into these activities. Murphy, Murphy and Shleifer (1991; 1993), show that the omnipresence of rent-seeking activity in an economy increases its rewards and attracts as a consequence human capital into that activity on the detriment of the productive activity.

So, we can deduce that innovation and investment are scarce in economies where rent-seeking activity is omnipresent. Furthermore, such institutional environment can compromise the effects of technological transfer from north to south economies, where rent-seeking activity is relatively developed. This can inhibit economic convergence and then amplify the gaps in product per capita between economies.

In this article, we propose an endogenous growth model with technological diffusion and rent-seeking activity. We will show that:

Technological transfer from north to south economies depends on the existence of a favourable institutional environment. The existence of social capability materialized by political and institutional stability is a necessary condition for the effective technological diffusion.

The convergence of poorer economies towards the GDP/capita of advanced economies requires an adequate institutional environment. The omnipresence of pressure groups reduces individual's incentive to invest and adopt new technologies. The gap between the North and the South would amplify and the product per capita would diverge.

Our approach here consists on an extension of Barro and Sala-i-Martin's model (1995). These authors have elaborated an endogenous growth model with technological diffusion. In equilibrium, the South catches up the rate of growth of the North but the gap of GDP/capita persists and it is explained by a productivity gap and a technological gap.

We will adopt this model and we will introduce rent-seeking activity in such a model as a manner of Rama (1993). We will show that: Gaps in GDP/capita between economies are explained by technological gaps and also by institutional gaps. Furthermore, we will show that technological gaps between North and South are also explained by deficient institutions.

\section{The Model}

\subsection{Hypothesis}

We adopt the hypothesis adopted by Barro and Sala-i-Martin (1995) (from H1 to H5) and we add an other hypothesis (H6) that introduces the rent seeking activity.

H1: we consider two economies: economy1, the leader of technology and economy2, the follower. Furthermore, we assume that the diffusion of technology corresponds to a diffusion of patents. Researchers in country2 imitate new technologies invented by country 1 without paying any fees to foreign innovators.

H2: Each economy is composed of two sectors: a R\&D sector and a final good sector.

In country 1 , the R\&D correspond to a sector of innovation and in economy 2 , this sector correspond to a sector of imitation and adoption of new technology to a different environment. The cost of imitation is typically less than the cost of innovation. 
H3: The technological progress corresponds to an increase in the number of varieties of intermediate input.

H4: Sector 2 (final good sector) is a competitive sector, whereas sector 1 (R\&D) is a monopolistic one. In this latter sector, each innovator (or imitator in economy2) monopolizes one variety of product and wins as a consequence a rent of monopoly.

H5: Final goods are tradable across countries and are exchanged at a single world price.

H6: We assume that there is an activity of rent seeking (RS) in each country: firms having the same political interest form lobbies or pressure groups in order to monopolize particular advantages (such as tariff barriers against foreign competitition). Any resources of the firm will be allocated to rent seeking activity and the regulations monopolized constitute a decision variable (or control variable) to the firm.

\subsection{Resolution of the Model}

2.2.1 Behaviour of Innovators in the Leading County

We adopt the model of Barro and Sala-i-Martin (1995) and we consider the production function of a representative firm as follows (Note 1):

$$
y_{1}=A_{1} L_{1}^{\alpha} \int_{1}^{N_{1}}\left(x_{1 j}\right)^{1-\alpha} d j ; 0<\alpha<1
$$

With $\mathrm{y}_{1:}$ the production of the firm;

$\mathrm{A}_{1}$ : a productivity parameter;

$\mathrm{L}_{1}$ : the quantity of labour input, which is assumed as a constant;

$\mathrm{x}_{1 \mathrm{j}}$ : the quantity of non durable input of type $\mathrm{j}$;

$\mathrm{N}_{1:}$ the number of variety of intermediate goods that has been discovered.

Recall that, in Barro and Sala-i-Martin's model (1995), the parameter $A_{1}$ is exogenous and it represents various aspects of government policy-such as taxation, the provision of public services and maintenance of property rights. All of these factors increase the global level of productivity in the economy. In our model, government policy represented by $A_{1}$ is assimilated to a trade policy and it is endogenous: we assume that firms having a common political interest would organise and lobby to serve that interest. Each firm would belong to one or more groups and the vector of pressures of these competing groups explain the outcomes of the political process. In our case, this common interest corresponds to restrictive reglementations against foreign competitition. We endogenese the government policy as in Rama (1993). The production function of the representative firm will then be represented as follows:

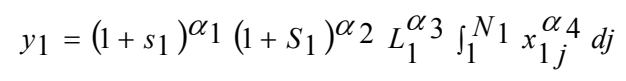

with $\mathrm{s}_{1}$ : the restrictive regulations monopolized by a representative firm in order to increase its productive efficiency.

$\mathrm{S}_{1}$ : the restrictive regulations monopolized by the other competitive firms looking to increase their productive efficiency and to reduce that of the representative firm. Thus $\mathrm{S}_{1}$ can be assimilated as an externality.

The rent seeking activity is assimilated to a strategic game (a repeated prisoner's dilemma) between many firms. Each firm can choose between two strategies:

-Participate in rent seeking and exert pressure on government in order to monopolize any particular advantage (any restrictive regulation) in its favour, but on the detriment of the other competitive firms;

-Participate in a competitive equilibrium where there are not any restrictive regulations.

The latter strategy is a Pareto efficiency one and it leads to a competitive equilibrium where there is not any restrictive regulations $(\mathrm{s}=\mathrm{S}=0$ ) and the global factor productivity is the highest possible. However, the number of firms is very large and they can't coordinate their actions in order to choose strategy two. The unique equilibrium is then a non cooperative one where $s=\mathrm{S}>0$. Furthermore, strategy two is the dominant strategy. In fact, if the representative firm does not participate in RS activity, it will be damaged because the other firms will participate and will monopolize regulations increasing their productivity but reduce that of the representative firm. Thus, in equilibrium we have $\mathrm{s}=\mathrm{S}>0$.

The parameters $\alpha_{1}, \alpha_{2}, \alpha_{3}$ and $\alpha_{4}$ verify the following inequalities:

$$
0<\alpha_{1}<1 ; \alpha_{2}<0 ; \alpha_{1}+\alpha_{2}<0 ; 0<\alpha_{3}<1 ; 0<\alpha_{4}<1
$$


The coefficient $\alpha_{2}$, is less than zero because the regulations monopolized by competitive firms reduce the productive efficiency of the representative firm. Furthermore, the restrictive reglementations monopolized by all firms reduce global efficiency of the economy, so that $\alpha_{1}+\alpha_{2}<0$.

We assume that, the returns to scale of this firm are constant, therefore

$$
\alpha_{1}+\alpha_{3}+\alpha_{4}=1
$$

We adopt the hypothesis of unisectoral model, where the aggregate product can be perfectly exchanged to different uses: consumption, production of intermediate inputs, research and development and rent seeking. All prices are expressed in terms of product $\mathrm{y}_{1}$

\section{Equilibrium in sector 1:}

The profit of the representative firm is equal to the income earned by the firm after selling its products minus the production cost including the cost of labor, the cost of intermediate inputs, minus the RS expenditures.

$$
\Pi_{1}=y_{1}-w_{1} L_{1}-\int_{1}^{N_{1}} p_{1 j} x_{1 j} d_{j}-l_{1} ; l_{1}=s_{1} \theta_{1} y_{1}
$$

Where:

$w_{1}$ : the wage rate in country 1 ;

$\mathrm{P}_{1 \mathrm{j}}$ : the price of intermediate input $\mathrm{j}$;

$l_{1}$ : the fraction of resources allocated to RS activity;

$\theta_{1}$ : the unit cost of one restrictive regulation.

In order to monopolize any restrictive reglementations or any particular advantages, the firm spends a fraction of its product equal to $\theta_{l} y_{l}$ (and in order to monopolize $s_{l}$ restrictive regulations, it must spend $s_{l} \theta_{l} y_{l}$ ). The parameter $\theta_{l}$ would reflect as a consequence the importance of RS activity in the economy. A high $\theta_{l}$ would increase the expenditures in lobbying and reduce the incentive of individuals to being rent seekers. As $\theta_{l}$ is high, the less important will be the rent seeking activity and more efficient will be the government.

The firm operates in a competitive regime and it possesses three control variables, $x_{1 j}, L_{1}$ and $s_{1}$. The maximisation of $\Pi_{1}$ with respect to these variables implies that the marginal product of each of this variable is equal to its price, let:

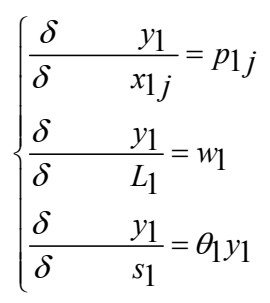

This maximisation's condition is sufficient because the production function is concave in $x_{1 j}$, in $L_{1}$ and in $s$.

The resolution of this system yields the demand function for intermediate $\mathrm{j}$ (Note 2) from all producers of goods in country 1 :

$$
x_{1 j}=A_{1} p_{1 j}^{\frac{1}{\alpha_{4}-1}} L_{1}^{\frac{-\alpha_{3}}{\alpha_{4}-1}} ; A_{1}=\left(\frac{1}{\alpha_{4}}\right)^{\frac{1}{\alpha_{4}-1}}\left(\frac{\theta_{1}}{\alpha_{1}}\right)^{\frac{\alpha_{1}+\alpha_{2}}{\alpha_{4}-1}}
$$

We assume that the marginal cost of production for the intermediate good $\mathrm{j}$ equals 1 . The flow of monopoly profit to the inventor is:

$$
\Pi_{1 j}=\left(p_{1 j}-1\right) x_{1 j}
$$

Substitution of the result for $\mathrm{x}_{1 j}$ into equation (2) and maximisation of $\Pi_{1 j}$ with respect to $\mathrm{p}_{1 j}$ yields the monopoly price (Note 3):

$$
p_{1 j}=p_{1}=\frac{1}{\alpha_{4}}>1
$$

This monopoly price is the same at all points of time and for all types of intermediate goods (Note 4). 
Substitution of the result for $\mathrm{p}_{1 \mathrm{j}}$ into equation (4) yields:

$$
x_{1 j}=x_{1}=A_{1} \alpha_{4}^{\frac{1}{1-\alpha_{4}}} L_{1}^{\frac{-\alpha_{3}}{\alpha_{4}-1}}
$$

The quantity is the same for all intermediates $j$ and at all points in time (because $\mathrm{L}_{1}$ is constant). Substitution of the result from equation (5) into the production function in equation (1) implies that country's 1 total output is (Note 5):

$$
Y_{1}=B_{1} \theta_{1}^{\frac{\alpha_{1}+\alpha_{2}}{\alpha_{4}-1}} N_{1} L_{1}^{\frac{-\alpha_{3}}{\alpha_{4}-1}} ; B_{1}=\alpha_{1}^{\frac{\alpha_{1}+\alpha_{2}}{1-\alpha_{4}}} \alpha_{4}^{\frac{2 \alpha_{4}}{1-\alpha_{4}}}
$$

Hence output per person $y_{l}=Y_{l} / L_{l}$ rises with the number of variety, with $\mathrm{N}_{1}$ and with $\theta_{1}$. The variable $\mathrm{N}_{1}$ represents the state of technology in country 1 . Increases in N1 leads to equiproportionate expansions in output per worker.

The variable $\theta_{1}$ represents the cost of one policy regulation. Increases in $\theta_{1}$ lead to an increase in output per worker. In fact increase in $\theta_{1}$ reduce the importance of pressure groups and reduce the incentive of individuals to being rent seekers.

This result confirms the institutionalist's thesis initiated by Olson (1983) and North (1981) where the omnipresence of pressure groups generates a decline of economy. Mechanisms through which rent seeking activity affect economic activity has been cited in section 1 .

Now, we go back to the resolution of our model in order to determine growth rate of economy. Substitution from equations (4) and (5) into equation (2) implies that the flow of monopoly profit to the owner of the rights to intermediate $\mathrm{j}$ is (Note 6):

$$
\Pi_{1 j}=D_{1} \theta_{1}^{\frac{\alpha_{1}+\alpha_{2}}{\alpha_{4}-1}} L_{1}^{\frac{-2 \alpha_{3}}{\alpha_{4}-1}} ; D_{1}=\frac{1-\alpha_{4}}{\alpha_{4}} \alpha_{4}^{\frac{2}{1-\alpha_{4}}}
$$

Since the profit flow is constant, the present value of profits from date $t$ onward is:

$$
V_{1}(t)=\int_{t}^{\infty} \prod_{1} e^{-\int_{t}^{s} r_{1}(v) d v} d s
$$

Where $r_{l}(v)$ is the real interest rate at time $\mathrm{v}$ in country 1 .

If there is free entry into $R \& D$ activity, the technological advantage held by the monopoly of intermediate $\mathrm{j}$ decreases progressively until it gets down to zero. Then $V_{1}(t)$ must equal to the constant cost of invention $\eta$ :

$$
V_{1}(t)=\eta_{1}
$$

This condition implies that $r_{l}(v)$ is constant over time and given by (Note 7):

$$
r_{1}=\frac{\Pi_{1}}{\eta_{1}}
$$

Substitution of $\Pi_{1}$ into equation (7) yields:

$$
n=\frac{L_{1}^{\frac{-2 \alpha_{3}}{\alpha_{4}-1}}}{\eta_{1}} D_{1} \theta_{1}^{\frac{\alpha_{1}+\alpha_{2}}{\alpha_{4}-1}}
$$

The rate of return is then a positive constant. This result is similar to the AK model where technology and incentive to invest maintain in permanence the rate of return at value $\mathrm{A}$.

\subsubsection{Household's Behaviour and Balanced Equilibrium}

Consumers in country 1 are of the usual Ramsey type with infinite horizons. At time 0 , these consumers seek to maximize

$$
U_{1}=\int_{0}^{\infty} e^{-\rho t} \frac{C_{1}^{1-\sigma}-1}{1-\sigma}
$$

with $\rho$ : the rate of time preference

$\sigma$ : the magnitude of the elasticity of the marginal utility of consumption. (The intertemporel elasticity of 
substitution is $\frac{1}{\sigma}$ ).

Maximisation of utility, subject to a standard budget constraint, leads to the usual formula for the growth rate of consumption.

$$
\frac{\dot{C}}{C}=\frac{1}{\sigma}(n-\rho)
$$

Substitution of the result from equation (8) into this equation yields:

$$
\gamma_{C}=\frac{1}{\sigma}\left(\frac{L_{1}^{\frac{-2 \alpha_{3}}{\alpha_{4}-1}}}{\eta_{1}} D_{1} \theta_{1}^{\frac{\alpha_{1}+\alpha_{2}}{\alpha_{4}-1}}-\rho\right)
$$

In the full equilibrium of this model, $Y_{l}$ and $N_{l}$ always grow at the same rate as $C_{I}$. In fact equation (6) shows that the ratio $\left(Y_{1} / N_{l}\right)$ is constant (because $\mathrm{L}_{1}$ is constant) and as a consequence $\mathrm{Y}_{1}$ and $\mathrm{N}_{1}$ grow at the same rate.

Furthermore, the level of consumption $\mathrm{C}$ must satisfy the budget constraint of the economy:

$$
C_{1}=Y_{1}-\eta \dot{N}_{1}-N_{1} X_{1}-l_{1} ; l_{1}=s_{1} \theta_{1} Y_{1}
$$

With $\eta N_{1}$ : resources allocated to research and development activity.

$N_{1} X_{1}$ : resources allocated to the acquisition of intermediate input.

$l_{1}$ : resources allocated to rent seeking activity

Recall that:

$$
\dot{N}_{1}=\gamma_{N_{1}} N_{1} ; \quad l_{1}=s_{1} \theta_{1} Y_{1} \text { and } s_{1}=\frac{\alpha_{1}}{\theta_{1}}-1=\text { cte }(\text { acccording to Note } 2)
$$

Thus $C_{1}=Y_{1}-\gamma_{N_{1}} N_{1} \eta-N_{1} X_{1}-s_{1} \theta_{1} \mathrm{Y}_{1}$. Therefore,

$$
\frac{C_{1}}{N_{1}}=\frac{Y_{1}}{N_{1}}-\eta \gamma_{N_{1}}-X_{1}-\frac{s_{1} \theta_{1} Y_{1}}{N_{1}}=c t e
$$

So $\left(C_{I} / N_{l}\right)$ is constant because the second term of equation (10) is constant. Subsequently $\mathrm{C}_{1}$ and $\mathrm{N}_{1}$ grow at the same rate:

$$
\gamma_{C_{1}}=\gamma_{Y_{1}}=\gamma_{N_{1}}
$$

The economy is then placed on a balanced growth path. Furthermore, we note that the growth rate of the economy, given by equation (9), is an increasing function of $\theta_{1}$, the unit cost of policy regulations. This result confirms again the institutionalist's thesis that RS activity affects the level of output per capita and also the growth rate of output.

\subsubsection{Behaviour of Imitators in the Following Country}

The form of the production function in country 2 is similar as that in country 1 :

$$
y_{2}=\left(1+s_{2}\right)^{\alpha_{1}}\left(1+S_{2}\right)^{\alpha_{2}} L_{2}^{\alpha_{3}} \int_{1}^{N_{2}}\left(x_{2 j}\right)^{\alpha_{4}}
$$

We assume that country 2 is technologically behind initially in the sense that $\mathrm{N}_{2}(0)<\mathrm{N}_{1}(0)$.

The parameter $\theta_{2}, L_{2}$ and the cost of innovation $\eta_{2}$ may differ from their counterparts in country 1 . The coping and adaptation of an intermediate good in country 1 for use in country 2 costs $v_{2}(t)$, where $v_{2}(0)<\eta_{2}$, so that imitation is initially more attractive than innovation for country 2.

Furthermore, we assume that the returns to innovation are constant and the number of potential inventions are unbounded whereas in imitation the situation is different, the returns are decreasing and the number of goods that can be copied at any point in time is limited to the finite number that have been discovered elsewhere (in country 1), so $N_{2}<N_{1}$.

Furthermore, we can admit that some inventions are more easily adapted and less costly imitated in country 2 , so that goods that were easier to imitate would be copied first and the cost $v_{2}$ would increase with the number already imitated. Thus we can assume that, $v_{2}$ is an increasing function of $\left(N 2 / N_{l}\right)$ : 


$$
v=v\left(\frac{N_{2}}{N_{1}}\right), v^{\prime} \succ 0 \text { and } v^{\prime \prime} \succ 0
$$

The equilibrium of the representative firm yields a monopoly price, $p_{2 j}=P_{2}=1 / \alpha_{4}$, determined as the same manner as in country 1 . Furthermore, the formulas for quantity produced of intermediate $j, x_{2 j}$, total output, $y_{2}$, and the flow of profit, $\Pi_{2 \mathrm{j}}$ are determined in an analogous manner as that for country 1 and are given respectively by :

$$
\begin{gathered}
x_{2 j}=x_{2}=A_{2} \alpha_{4}^{\frac{1}{1-\alpha_{4}}} L_{2}^{\frac{-\alpha_{3}}{\alpha_{4}-1}} ; A_{2}=\left(\frac{1}{\alpha_{4}}\right)^{\frac{1}{\alpha_{4}-1}}\left(\frac{\theta_{2}}{\alpha_{1}}\right)^{\frac{\alpha_{1}+\alpha_{2}}{\alpha_{4}-1}} \\
Y_{2}=B_{2} \theta_{2}^{\frac{\alpha+\alpha_{2}}{\alpha_{4}-1}} N_{2} L_{2}^{\frac{-\alpha_{3}}{\alpha_{4}-1}} ; B_{2}=\alpha_{1}^{\frac{\alpha_{1}+\alpha_{2}}{1-\alpha_{4}}} \alpha_{4}^{\frac{2 \alpha_{4}}{1-\alpha_{4}}} \\
\prod_{2 j}=D_{2} \theta_{2}^{\frac{\alpha_{1}+\alpha_{2}}{\alpha_{4}-1}} L_{2}^{\frac{-2 \alpha_{3}}{\alpha_{4}-1}} ; D_{2}=\frac{1-\alpha_{4}}{\alpha_{4}} \alpha_{4}^{\frac{2}{1-\alpha_{4}}}
\end{gathered}
$$

The present value of profits from imitation of intermediate $\mathrm{j}$ in country 2 is:

$$
V_{2}(t)=\int_{t}^{\infty} \prod_{2} e^{-\int_{t}^{s} r_{2}(v) d v} d s
$$

Where $v_{2}(t)$ is the rate of return in country 2 at time $\mathrm{v}$.

If there is free entry into the imitation activity then $v_{2}(t)$ must equal the cost of imitation $v_{2}(t)$ at each point in time:

$$
V_{2}(t)=v_{2}\left(\frac{N_{2}}{N_{1}}\right)
$$

This formula allows us to derivate the rate interest $r_{2}$ :

$$
r_{2}=\frac{\prod_{2}}{v_{2}}+\frac{\dot{v}_{2}}{v_{2}}
$$

Hence, the rate of return in country 2 would not be constant, it would equal to the ratio of profit to the lump-sum cost of obtaining this profit $\left(\frac{\prod_{2}}{v_{2}}\right)$ plus an additional term, the gain in capital $\left(\dot{v}_{2} / v_{2}\right)$.

We consider a representative consumer in country 2 having the same preferences as consumers in country 1 . His optimisation condition implies that:

$$
\frac{\dot{C}_{2}}{C_{2}}=\frac{1}{\phi}\left(r_{2}-\rho\right)
$$

This condition is determined as the same manner as in section (2.2.2).

\section{Steady-State Growth}

In the steady state, the technological gap $\left(N_{2} / N_{l}\right)$ will be constant and equal to $\left(N_{2} / N_{l}\right)^{*}$. Furthermore, from equation (15), we can deduce that the rate of return in country 2 will be constant and it equals $\left(\Pi_{2} / v_{2}\right)$ :

$$
r_{2}=\frac{\prod_{2}}{v_{2}}
$$

Substitution of $\Pi_{2}$ into equation (17) yields:

$$
r_{2}=\frac{D_{2}}{v_{2}} \theta_{2}^{\frac{\alpha_{1}+\alpha_{2}}{\alpha_{4}-1}} \frac{-2 \alpha_{3}}{L_{2}^{\alpha_{4}-1}} ; D_{2}=\frac{1-\alpha_{4}}{\alpha_{4}} \alpha_{4}^{\frac{2}{1-\alpha_{4}}}
$$


Substitution of $r_{2}$ into equation (16) yields:

$$
\frac{\dot{C}_{2}}{C_{2}}=\frac{1}{\phi}\left(\frac{d_{2}}{v_{2}} \theta_{2}^{\frac{\alpha_{1}+\alpha_{2}}{\alpha_{4}-1}} L_{2}^{\frac{-2 \alpha_{3}}{\alpha_{4}-1}}-\rho\right)
$$

We can show easily, as in section 2.2.2, that economy 2 is at steady state and $N_{2}, Y_{2}$ and $C_{2}$ grow at a constant rate $r_{2}$. Furthermore, as economy 2 is characterized by technological lateness, the rate of growth of its technology is higher than that of country 1 (theory of caching up), so that:

$$
\gamma_{N 2}>\gamma_{N 1}
$$

Thus the ratio $\left(N_{2} / N_{l}\right)$ will grow and the cost of imitation will increase (Note 8). Individuals in country 2 have never incentives to imitate; $\gamma \mathrm{N} 2$ will decrease until it reaches $\gamma_{N 1}$. So that $\gamma_{N 1}=\gamma_{N 2}$.

Given the fact that each economy is placed on a balanced growth path, we can deduce that in equilibrium:

$$
\gamma_{N 1}=\gamma_{C 1}=\gamma_{Y 1}=\gamma_{N 2}=\gamma_{C 2}=\gamma_{Y 2}
$$

In the long run, economy 2 reaches economy 1 through the process of technological diffusion. However, this process does not imply any convergence of product per capita between the two countries (Note 9). In fact, the ratio of the product per capita between the two economies equals to:

$$
\left(\frac{Y_{2}}{Y_{1}}\right)^{*}=\left(\frac{\theta_{2}}{\theta_{1}}\right)^{\frac{\alpha_{1}+\alpha_{3}}{\alpha_{4}-1}}\left(\frac{N_{2}}{N_{1}}\right)\left(\frac{L_{2}}{L_{1}}\right)^{\frac{-\left(\alpha_{3}+\alpha_{4}\right)-1}{\alpha_{4}-1}}
$$

The linearization of equation (19) gives the product per capita's gap between the two economies and it equals to:

$$
\underbrace{\operatorname{Ln}\left(\frac{Y_{2}}{Y_{1}}\right)^{*}}_{\text {GDP/capita gap }}=\frac{\alpha_{1}+\alpha_{3}}{\alpha_{4}-1} \underbrace{\operatorname{Ln}\left(\frac{\theta_{2}}{\theta_{1}}\right)}_{\text {institutionnel gap }}+\underbrace{\operatorname{Ln}\left(\frac{N_{2}}{N_{1}}\right)}_{\text {technological gap }}+\frac{-\left(\alpha_{3}+\alpha_{4}\right)-1}{\alpha_{4}-1} \underbrace{\operatorname{Ln}\left(\frac{L_{2}}{L_{1}}\right)}_{\text {scale benefit gap }}
$$

Thus, the gap between the product per capita of country 1 and that of country 2 persists and it depends on the technological gap (as in Barro et Sala-i-Martin's model), on the institutional gap and on the gap of scale benefits (Note 10).

Thus the convergence of country 2 towards the GDP/capita of country 1 implies the existence of a favorable institutional environment. Uncertainty about property rights delays convergence simply by deterring investment. This prevents these countries from taking advantage of the greater returns.

Furthermore, we can show that in equilibrium, the technological gap is also explained by institutional differences. This can be illustrated as follows:

Recall that in equilibrium, we have: and $\gamma_{C l}=\gamma_{C 2}$ the individual's preferences are similar in the two countries, then we can deduce that:

$$
r_{1}=r_{2}
$$

The substitution of $r_{1}$ and $r_{2}$ respectively into equation (19) yields:

$$
\begin{aligned}
\frac{\prod_{1}}{\eta_{1}} & =\frac{\prod_{2}}{v_{2}} \\
\text { Thus } v_{2} & =\eta_{1}\left(\frac{\prod_{2}}{\prod_{1}}\right)
\end{aligned}
$$

Furthermore, the substitution of $\Pi_{1}$ and $\Pi_{2}$ respectively into (20) yields:

$$
v_{2}=\eta_{1}\left(\frac{\theta_{2}}{\theta_{1}}\right)^{\alpha_{1}+\alpha_{2}}\left(\frac{L_{2}}{L_{1}}\right)^{\frac{-2 \alpha_{3}}{\alpha_{4}-1}}
$$

Now, assume that the cost of imitation in equation (12) takes the constant elasticity form:

$$
v_{2}=\eta_{2}\left(\frac{N_{2}}{N_{1}}\right)^{\sigma} ; \sigma>0
$$


Where $\sigma$ is the elasticity of $v_{2}$ with respect to $\left(N 2 / N_{1}\right)$.

Note that $v_{2}$ approaches $\eta_{2}$ as $\left(N 2 / N_{l}\right)$ approaches 1 .

Equations (21) and (22) imply that the steady state ratio of $N_{2}$ to $N_{l}$ is given by:

$$
\left(\frac{N_{2}}{N_{1}}\right)^{*}=\left[\left(\frac{\eta_{1}}{\eta_{2}}\right)\left(\frac{\theta_{2}}{\theta_{1}}\right)^{\frac{\alpha_{1}+\alpha_{2}}{\alpha_{4}-1}}\left(\frac{L_{2}}{L_{1}}\right)^{\frac{-2 \alpha_{3}}{\alpha_{4}-1}}\right]^{\frac{1}{\sigma}}
$$

The linearization of equation (20) gives technological gap between the two economies and it equals to:

$$
\underbrace{\operatorname{Ln}\left(\frac{N_{2}}{N_{1}}\right)^{*}}_{\text {techno log ical gap }}=\frac{1}{\sigma}[\operatorname{Ln}\left(\frac{\eta_{1}}{\eta_{2}}\right)+\frac{\alpha_{1}+\alpha_{2}}{\alpha_{4}-1} \underbrace{\operatorname{Ln}\left(\frac{\theta_{2}}{\theta_{1}}\right)}_{\text {institutionnal gap }}-\frac{2 \alpha_{3}}{\alpha_{4}-1} \underbrace{\operatorname{Ln}\left(\frac{L_{2}}{L_{1}}\right)}_{\text {scale benefit gap }}]
$$

In the long run the technological gap between the two economies persists and it is explained partially by institutional differences. The existence of a sufficient degree of social capability materialized by a favourable institutional and political environment is a necessary condition for technological catching up.

From the preceding results, we can conclude that:

1) The disparity of GDP/capita between countries is partially explained by institutional disparity. The convergence of poor economy towards a high equilibrium implies the existence of an adequate institutional climate.

2) Such institutional climate is a necessary condition for the technological catching up.

\section{Empirical Analyses}

Our purpose in this section is to study the empirical significance of the results shown above: The convergence of a poor economy to GDP / capita of an advanced economy imply the existence of an appropriate institutional environment. Institutional differences between these economies translate into differences in their per capita product. To this end, we estimate an equation inspired from results of theoretical model in the previous section:

$$
\left(\frac{Y_{2}}{Y_{1}}\right)=\operatorname{cst}+a\left(\frac{\theta_{2}}{\theta_{1}}\right)+b\left(\frac{N_{2}}{N_{1}}\right)+c\left(\frac{L_{2}}{L_{1}}\right)+\mu
$$

According to the model, $\mathrm{a}, \mathrm{b}$ and $\mathrm{c}$ are positive parameters.

We consider five Arab Mediterranean countries (Tunisia, Morocco, Algeria, Egypt and Syria) during the period 2001-2010.

We believe that the United States of America (USA) is the world technological leader; so the equation to be estimated is as follows:

$$
\left(\frac{Y_{i t}}{Y U S A t}\right)=k+a\left(\theta_{\mathrm{i}, \mathrm{t}}\right)+b\left(\frac{N_{i, t}}{N_{U S A, t}}\right)+c\left(\frac{L_{i, t}}{L_{U S A, t}}\right)+\mu_{i t}
$$

Where $k$ is a constant and $\mu i t$ is a random term.

We Note that:

-Yit: gross domestic product per capita of the economy $i$ at time $\mathrm{t}$,

-YUSAt: gross domestic product per capita of United States of America at time $t$,

-Nit : the level of technological development of economy i at time $t$,

-Nusat: the technological level of the United States of America at time $t$,

-Lit : the population size of the economy i at time $\mathrm{t}$,

-Lusa,t: the size of the population of the United States of America at time $t$,

- $\theta i t$ : measuring the level of institutional development of the economy $i$ at time $t$.

The institutional gap, $\left(\theta_{2} / \theta_{\text {USA }}\right)$ mentioned in equation (21), is replaced by $\theta i t$, the quality of institutions in the 
South since the ratio of two qualitative variables, used to approximate the institutional gap does not make economic sense. So it is more convenient to estimate the ratio of GDP / capita between economies according to the quality of governance in the economies of the South. High institutional level in these economies leads to low disparities in income per capita between the North and South countries.

Note that in this work, the level of institutional development in an economy depends on the degree of openness of the insider system or the extent of rent-seeking activity prohibiting institutional transition to an impersonal and formalized mode of production of confidence. In this regard, Ould Aoudia et al. (2007) proposed a set of indicators that describe the degree of openness of the system of social regulation and which correspond to economic, political and social openness:

Economic openness: (1) regulation of competition, (2) ease of starting a business, (3) ease of entry, (4) dispersed ownership, (5) information on the capital of companies.

Social openness: (1) social mobility (2) no segmentation of the labor market and non-discrimination based on ethnic, religious or gender criteria (3) training of elites (4) freedom of association.

Political openness: (1) political rights and civil liberties (2) pluralism (3) decentralization, (4) transparent consultation process.

We construct a synthetic indicator which represents the first principal component of these indicators (Note 11). We consider a panel composed of five Arab Mediterranean countries (Tunisia, Morocco, Algeria, Egypt and Syria) during the period 2001-2010. The non-availability of institutional data over a long period forced us to limit to 10 years. Similarly, the unavailability of economic and institutional data for other countries in the region forced us to limit our sample to five countries. United States of America (USA) are the technological leader in this sample; they are located on the world technology frontier. Also, they are characterized by a level of institutional development relatively advanced. They are characterized by a culture of governance based primarily on formal rules and also an ability of States to coordinate private interests in the direction of the general interest (Souissi, 2013).

\subsection{Data Sources}

The gross domestic product per capita (measured in PPP and expressed in constant \$), the population size and the level of technological development of an economy are extracted from the CD-ROM of the World Bank (WDI, 2011) for the period 2001-2010 (Note 12). The level of technological development of an economy is approximated by the value (in current \$) of exports incorporating high technology and highly intensive in research and development such as aerospace products, computers, pharmaceuticals, scientific instruments and electrical machines.

The different institutional indicators mentioned above are extracts from the data base of "Institutional Profiles" of 2001, 2006 and 2009. Concerning the observations of 2001 and 2006, the institutional indicators are assumed held constant over a period of four years; in fact institutional change is long since historical and social factors exert resistance on their developments. The 2001 survey is spread along the period 2001-2004 and the 2006 is deployed along the period 2005-2007. The 2009 survey is extended along the period 2008-2010.

\subsection{Empirical Results}

The estimation of a panel data model requires firstly the verification of the homogeneous or heterogeneous specification of the sample. Fisher statistics, associated with the test of homogeneity, shows the existence of heterogeneity or country-specific individual effects. In addition, a descriptive study of the sample shows a high inter-individual variability (variability between) for over-the intra-individual variability (variability within) which confirms our econometric results on the existence of an individual effect. The model is then a model of individual effect. The haussman test shows that the individual effect is fixed. Moreover, since we have two endogenous variables in the model (Governance it and Nit / Nusa, t) (Note 13), we use the method of instrumental variables applied to the fixed effects model, which provides unbiased and convergent estimators. The instruments must be highly correlated with the variables to be instrumented and not with residues (verification of the orthogonality condition). Thus a $\mathrm{z}$ instrument must satisfy two conditions: $i$ ) $\mathrm{z}$ must be correlated with the endogenous explanatory variable and $i i) \mathrm{z}$ must be uncorrelated with the error term: $\mathrm{E}\left(\mathrm{Z}^{\prime} \mu\right)$ $=0, \mu$ is the error term of the structural model. Our estimation involves two steps: In a first step, we are interested with instrumentation of the endogenous variables using ordinary least squares:

$$
\begin{gathered}
N i t / \text { Nusat }=a+B X i t+\alpha Z i t+\quad i t \\
\text { Governance it }=b+C X i t+\beta Z i t+\quad \text { it }
\end{gathered}
$$


$X$ is the vector of exogenous variables in the model, $Z$ is the vector of instrumental variables, and are error terms.

To instrument "Governance", several instruments exogenous to the model have been proposed in the literature (Note 14).

However, since we have a second endogenous variable (Nit / Nusat) in our model, our choice of instruments will be limited because an economic reason must justify the use of a particular instrument for each of the endogenous variables.

We used two types of instruments: instruments selected from the model (endogenous variables lagged one period and the exogenous variables lagged one period) and an exogenous instrument of our model "the literacy rate". This rate was used by Berthelier, Desdoigts and OuldAoudia (2003) to instrument the institutional variables. The economic reasons that justify the use of such an instrument are that the level of instruction and education of the population can influence the formation and development of the institutions of governance. Similarly, such a level of education can promote the absorption of new technology and correspondingly reduced the technological gap between the North and South.

So, the instruments used are the following:

- (Li/Lusa) $t-1$ : the one period lag of the variable $L i / L u s a t$;

-(Ni/Nusa) $t-1$ : the one period lag of the variable NitNusat;

-(governance) $i, t-1$ : the one period lag of the variablegovernance it;

-literacy rate it.

These instruments are highly correlated with the endogenous explanatory variables since coefficients of correlation between the instruments and the instrumented variables are significant at the $5 \%$ level. Moreover, the results of the estimation of equations of instrumentation variables Governance it and Nit / Nusat show strong explanatory power and statistical significant overall Fisher. This allows us to conclude that the instruments are pertinent.

In a second step, we are interested with estimating the structural equation model. We use the instrumental variable method applied to the fixed effect model. The estimation results are presented in the table below and are consistent with theoretical predictions. The coefficients associated with the technology gap and the gap scale of production are positive (Note 15) and significant and this respectively, for a risk level of $5 \%$ and $1 \%$. The coefficient associated with the variable (Governance) is positive and significant for a degree of risk of $10 \%$.

Finally, the application of the test of over-identification of Sargan (1957) (Note 16) shows that the null hypothesis can't be rejected, so the instruments are not correlated with the error term. Consequently, the instruments are valid.

In terms of economic interpretation, the results (table 1) show that, the product per capita in the Mediterranean Arab Countries compared to the United States is sensitive to the difference in the scale of production, technological gap and the quality of institutions in the Mediterranean Arab Countries, which is consistent with our theoretical predictions. An increase of scale of production of the Mediterranean Arab Countries compared to that of USA causes a narrowing of the gap in per capita product; a decrease of technological gap between these economies lowers the gap in per capita product and the opening of the system of social regulation, the participation of citizens in economic, political and social life in the Mediterranean Arab Countries will reduce disparities in income per capita between these economies and advanced economies. 
Table 1. Economic convergence in Mediterranean Arab countries: empirical resultsdependent variable (yi,t/yusa,t)

\begin{tabular}{ll}
\hline Constante & $-0.075(-1.61)$ \\
Ni,t/Nusa,t & $0.135(2.39)^{* *}$ \\
Li,t/Lusa,t & $1.752(4.23)^{* * *}$ \\
Gouvernancei,t & $0.007(1.89)^{*}$ \\
$\mathrm{R}^{2}$ & 0.116 \\
Number of observations & 45 \\
Method of estimation & Method of instrumental variables applied to fixed effects model (2) \\
\hline instruments used $(\mathrm{Z})$ & (Li/Lusa) t-1 \\
& (Ni/Nusa) t-1 \\
& Literacy rate it \\
\multicolumn{1}{c}{ Sargan test } & Governance it-1 \\
\hline
\end{tabular}

Notes: The values in parentheses are the t-student of estimated coefficients.

$(* * *)$ The coefficients are significant to a level of $1 \%$ risk.

(**) The coefficients are significant for a risk level of $5 \%$.

(*) The coefficients are significant to a degree of risk of $10 \%$.

(1) The p-value associated with the Sargan test. This result shows that we must accept the hypothesis H0: instruments are not correlated with the error term. Using the method of instrumental variable, the R2 is not an appropriate measure of explanatory power. Sources: Mauro (1995) "The effects of Corruption on Growth, Investment, and Government Expenditure": A Cross-Country Analysis. "Barro (1991) International Business, Political Risk Services, Inc .” IRIS Center, University of Maryland.

\section{Conclusion}

Analyzes of underdevelopment have focused on the necessity of attracting new technology in order to improve the labour productivity in developing countries. Many experiences of technological transfer have failed. Reasons of this failure have not been analysed deeply. The institutional approach initiated by Olson (1983), North (1981) and extended by Abramovitz (1986) and others propose an interesting explication. In fact, this approach insists on the necessity of having favourable institutions in the host countries in order to provide an effective technological transfer and to held backward economies to catch up a higher equilibrium.

Our approach here consists of linking the problems inherent to technology transfer and to convergence of product per capita with institutional aspects. We construct a model of endogenous growth with technological diffusion and in the presence of a rent-seeking activity. Our approach consists on an extension of Barro and Sala-i-Martin's model (1995), which we have introduced the rent seeking activity as the manner of Rama (1990). Our results confirm the suggestions of institutionalist. In fact we showed that the weight of institutions can inhibit the diffusion of technology and amplify disparities of GDP/capita between countries. The omnipresence of rent seeking activity in developing countries reduces individual's incentive to invest and to adopt new technologies. The gap between the North and the South would amplify and the product per capita would diverge. Furthermore, we have accomplished an empirical validation on a panel of the Mediterranean Arab Countries during the period 2000-2010. The application of instrumental variables method was shown that, the opening of the system of social regulation in these economies reduce gaps of output per capita between Mediterranean Arab Countries and developed countries. Such considerations lead to political institutional choices that fight against all forms of rent-seeking and ensure optimal allocation of resources. Our contribution in this work includes also the construction of a composite indicator that measures the degree of openness of the insider system or the importance of rent-seeking activity in an economy. This is the first principal component of a set of indicators proposed by OuldAoudia and Meisel (2008, p 43), reflecting the degree of openness of the system of social regulation and which correspond to economic, political and social openness.

\section{References}

Abramotiz, M. (1986). Catching up, forging ahead, and falling behind. Journal of Economic History, XLVI, 385406. http://dx.doi.org/10.1017/S0022050700046209

Barrett, C. B. (1997). Idea gaps, objet gaps, and trust gaps in economic development. The Journal of Developing Areas, 31, 553-568.

Barro, R. J., \& Sala-i-M, X. (1995). Technological diffusion, convergence, and growth. NBER Working Paper, June, n5151. 
Berthelier, P., Desdoigts, A., \& Jacques, O. A. (2003). Profils institutionnels, présentation et analyse d'une base de données originale sur les caractéristiques institutionnelles des pays en développement, en transition et développés. Documents de travail de la DGTPE No 2003/07. MINEFE.

Buchanan, J. M. (1980). Rent seeking and profit seeking. In McNutt, P. A. (Ed.), The economics of public choice. Cheltenham, UK: Edward Elgar.

Catusse, M. (2009). A propos de l'Entrée en Politique des. Entrepreneurs.

El Morched, B. (2008). Recherche de rente et processus de réformes politiques et institutionnelles dans le monde arabe: la leçon marocaine, equity and economic development. ERF 15 th Annual Conference 23-25 Novembre 2008.

Hansson, P., \& Henrekson, M. (1997). Caching up, social capability, government size and economic growth. In Bergstrom, V. (Ed.), Government and growth. New York: Clarendon Press Oxford Inc.

Keefer, P., \& Knack, S. (1995). Institutions and economic performance: Cross-country tests using alternative $\begin{array}{lllll}\text { institutional measures. Economics and } & \text { 207-227. }\end{array}$ http://dx.doi.org/10.1111/j.1468-0343.1995.tb00111.x

Keefer, P., \& Knack, S. (1997). Why don't poor countries catch up? A cross-national test of an institutional explanation. Economic Inquiry, XXXV, 590-602. http://dx.doi.org/10.1111/j.1465-7295.1997.tb02036.x

Meisel, N. (2004). Culture de gouvernance et développement. Intérêt de l'expérience française dans la gouvernance des entreprises pour les pays en développement et les économies émergentes, Paris: Editions de l'OCDE. http://dx.doi.org/10.1787/9789264017306-fr

Michalet, C. A., \& Sereni, J. P. (2006). L'articulation gouvernance publique-gouvernance privée au Maghreb et son impact sur l'investissement privé. Les cas de l'Algérie et de la Tunisie. Paris: OCDE.

Muller, D. C. (1989). Public Choice II. Cambridge University Press.

Murphy, K., Vishny, R., \& Shleifer, A. (1991). The allocation of talent: Implications for growth. The Quarterly Journal of Economics. http://dx.doi.org/10.2307/2937945

Murphy, K., Vishny, R., \& Shleifer, A. (1993). Why is rent Seeking so costly to growth. The Américan Economic Review, 83(2), 409-414.

Nabli, M. K., Silva, C., \& Aysan, A. F. (2008). Autoritarisme politique, crédibilité des réformes et développement du secteur privé au moyen-orient et en afrique du nord. Revue D'économie du Développement, 22(3), 49-85. http://dx.doi.org/10.3917/edd.223.0049

North, D. C. (1981). Structure and change in economic history. New York: Norton.

North, D. C. (1990). Institutions, institutional change and economic performance. Cambridge: Cambridge University Press. http://dx.doi.org/10.1017/CBO9780511808678

Olson, M. (1965). The logic of collective action: Public goods and the theory of groups. Cambridge, MA: Havard University Press.

Olson, M. (1982). The rise and decline of nations: Economic growth, Stagflation, and Social rigidities. New Haven and London: Yale University Press.

Ould, A. J. (2006). Croissance et réformes dans les pays arabes méditerranéens. Agence Française de Développement Département de la Recherche.

Ould, A. J., \& Meisel, N. (2008). La 'Bonne Gouvernance' est-elle une bonne stratégie de développement? Documents de travail de la DGTPE. MINEFE.

Parente, S. L., \& Prescott, E. C. (1999). Monopoly rights: A barrier to riches. American Economic review, 89, 1216-1234. http://dx.doi.org/10.1257/aer.89.5.1216

Peltzman, S. (1976). Toward a more general theory of regulation. Journal of Law and Economics, 19(2). http://dx.doi.org/10.1086/466865

Rama, M. (1990). Rent seeking and economic growth. A theoretical model and some empirical evidence. Journal of Development Economics, 42, 35-50. http://dx.doi.org/10.1016/0304-3878(93)90071-T

Souissi, N. (2013). Gouvernance publique et croissance économique dans les pays arabes de la méditerrané. Thèse de doctorat en sciences économiques, Faculté des Sciences Economiques et de Gestion de Tunis.

Tullock, G. (1967). The welfare costs of tariffs, monopolies and theft. The Western Economic Journal, 5, 224- 
232. Retrieved from http://www.databank.worldbank.org

\section{Notes}

Note 1. Thisproduction function is also adopted by Romer (90), Grossman and Helpman (91), Rivera Batizand Romer (91).

Note 2. Proof.

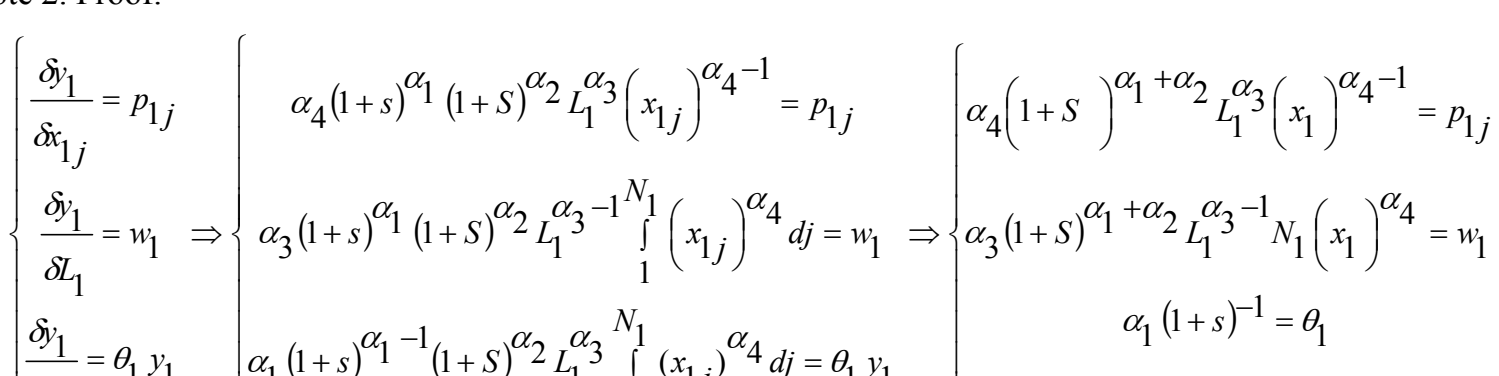

$$
\begin{aligned}
& \Rightarrow 1+s=\frac{\alpha_{1}}{\theta_{1}} \quad \text { (we have used theidentity s=S; see text) }
\end{aligned}
$$

If we substitute $(1+\mathrm{s})$ by its value in equation (1), we obtain:

$$
\begin{aligned}
& \alpha_{4}\left(\frac{\alpha_{1}}{\theta_{1}}\right)^{\alpha_{1}+\alpha_{2}} L_{1}^{\alpha_{3}} x_{1}^{\alpha_{4}-1}=p_{1 j} \\
& \Rightarrow x_{1}^{\alpha_{4}-1}=p_{1 j} \frac{1}{\alpha_{4}}\left(\frac{\alpha_{1}}{\theta_{1}}\right)^{-\left(\alpha_{1}+\alpha_{2}\right)} L_{1}^{-\alpha_{3}} \\
& \Rightarrow x_{1}=p_{1 j}^{\frac{1}{\alpha_{4}-1}} \underbrace{\left(\frac{1}{\alpha_{4}}\right)^{\frac{1}{\alpha_{4}-1}}\left(\frac{\theta_{1}}{\alpha_{1}}\right)^{\frac{\alpha_{1}+\alpha_{2}}{\alpha_{4}-1}}}_{A_{1}} L_{1}^{\frac{\alpha_{3}}{\alpha_{4}-1}}
\end{aligned}
$$

$\Rightarrow x_{1 j}=A_{1} P_{1 j}^{\frac{1}{\alpha_{4}-1}} L_{1}^{\frac{-\alpha_{3}}{\alpha_{4}-1}}$ which is a decreasing function of price.

Note 3. Proof.

$$
\begin{gathered}
\Pi_{1 j}=\left(p_{1 j}-1\right) x_{1 j} \\
=\left(p_{1 j}-1\right) A_{1} p_{1 j}^{\frac{1}{\alpha_{4}-1}} \frac{-\alpha_{3}}{L_{1}-1} \\
=A_{1} p_{1 j}^{\frac{\alpha_{4}}{\alpha_{4}-1}} \frac{-\alpha_{3}}{L_{1}^{\alpha_{4}-1}}-A_{1} p_{1 j}^{\frac{1}{\alpha_{4}-1}} \frac{-\alpha_{3}}{L_{1}^{\alpha_{4}-1}} \\
\frac{\delta \Pi_{1 j}}{\delta p_{1 j}}=0 \Leftrightarrow \frac{\alpha_{4}}{\alpha_{4}-1} A_{1} P_{1 j}^{\frac{1}{\alpha_{4}-1}} L_{1}^{-\frac{\alpha_{3}}{\alpha_{4}-1}}-\frac{1}{\alpha_{4}-1} A_{1} L_{1}^{-\frac{\alpha_{3}}{\alpha_{4}-1}} p_{1 j}^{\frac{2-\alpha_{4}}{\alpha_{4}-1}}=0 \\
\Leftrightarrow p_{1 j}=\frac{1}{\alpha_{4}} \succ 1
\end{gathered}
$$

Note 4 . We can verify thatthismonopoly pricecan bewrittenas:

$$
p_{1}=\frac{\text { marginal cost }}{1+\frac{1}{e}} \text { with } e \text { : }
$$

the elasticity of demand with respect toprice and $\left(1+\frac{1}{e}\right)^{-1}$ : the margin rate of monopoly.

Note 5. Proof.

The substitution of $\mathrm{x}_{1 \mathrm{j}}$ by its value in equation (1) gives us: 


$$
\begin{aligned}
& Y_{1}=(1+S)^{\alpha+\alpha_{21}} L_{1}^{\alpha_{3}} N_{1}\left(x_{1}\right)^{\alpha_{4}} \\
& Y_{1}=\left(\frac{\alpha_{1}}{\theta_{1}}\right)^{\alpha_{1}+\alpha_{2}} L_{1}^{\alpha_{3} N_{1}}\left(A_{1} \alpha_{4}^{\frac{1}{1-\alpha_{4}}} \frac{-\alpha_{3}}{\alpha_{1}^{\alpha_{4}-1}}\right)^{\alpha_{4}} \\
& =\left(\frac{\alpha_{1}}{\theta_{1}}\right)^{\alpha_{1}+\alpha_{2}} L_{1}^{\alpha_{3}}\left[\frac{1}{\alpha_{1}^{1-\alpha_{4}}}\left(\frac{\theta_{1}}{\alpha_{1}}\right)^{\frac{\alpha_{1}+\alpha_{2}}{\alpha_{4}-1}} \frac{1}{\alpha_{4}^{1-\alpha_{4}}} L_{1}^{-\frac{\alpha_{3}}{\alpha_{4}-1}}\right]^{\alpha_{4}} \\
& =\left(\frac{\theta_{1}}{\alpha_{1}}\right)^{\frac{\alpha_{1}+\alpha_{2}}{\alpha_{4}-1}}{ }_{N_{1} L_{1}}^{-\frac{\alpha_{3}}{\alpha_{4}-1}} \alpha_{4}^{\frac{2 \alpha_{4}}{1-\alpha_{4}}} \\
& =\theta_{1}^{\frac{\alpha_{1}+\alpha_{2}}{\alpha_{4}-1}} \underbrace{\frac{\alpha_{1}+\alpha_{2}}{\alpha_{1}^{1-\alpha_{4}}} \alpha_{4}^{\frac{2 \alpha_{4}}{1-\alpha_{4}}}}_{B_{1}} L_{1}^{-\frac{\alpha_{3}}{\alpha_{4}-1}} N_{1} \\
& \Rightarrow Y_{1}=B_{1} \theta_{1}^{\frac{\alpha_{1}+\alpha_{2}}{\alpha_{4}-1}} N_{1} L_{1}^{\frac{-\alpha_{3}}{\alpha_{4}-1}}
\end{aligned}
$$

Note 6. Proof.

$$
\begin{aligned}
& \Pi_{1 j}=\left(p_{1 j}-1\right) x_{1 j} \\
&=\left(\frac{1}{\alpha_{4}}-1\right) A_{1} \alpha_{4}^{\frac{1}{1-\alpha_{4}}} L_{1}-\frac{\alpha_{3}}{\alpha_{4}-1} \\
&=\frac{1-\alpha_{4}}{\alpha_{4}} \alpha_{4}^{\frac{1}{1-\alpha_{4}}}\left(\frac{\theta_{1}}{\alpha_{1}}\right)^{\frac{\alpha_{1}+\alpha_{2}}{\alpha_{4}-1}}-\frac{\alpha_{3}}{L_{1}} \frac{1}{\alpha_{4}-1} \alpha_{4}^{1-\alpha_{4}} \frac{-\alpha_{3}}{L_{1} \alpha^{-1}} \\
&=\theta_{1}^{\frac{\alpha_{1}+\alpha_{2}}{\alpha_{4}-1}} \frac{-2 \alpha_{3}}{L_{1}^{\alpha_{4}-1}} \underbrace{\frac{1-\alpha_{4}}{\alpha_{4}} \alpha_{4}^{\frac{1-\alpha_{4}}{1-\alpha_{4}}}}_{D_{1}} . \\
& \Rightarrow \Pi_{1 j}=D_{1} \theta_{1}^{\frac{\alpha_{1}+\alpha_{2}}{\alpha_{4}-1}} \frac{-2 \alpha_{3}}{L_{1}^{\alpha_{4}-1}}
\end{aligned}
$$

Note 7. Proof.

$$
V_{1}(t)=\int_{t}^{\infty} \Pi_{1} e^{-\int_{t}^{s} r_{1}(v) d v} d s=\eta
$$

We pose $R_{1}(v)$ the primitive of $r_{1}(v)$, thus $R_{\mathrm{i}}=r_{1}(s)$

$$
\begin{aligned}
\Rightarrow \quad-\int_{t}^{s} r_{1}(v) & =[R(v)]_{t}^{s} \\
& =-R(s)+R(t)
\end{aligned}
$$

As a result, (a) implies that:

$$
\begin{gathered}
\int_{t}^{\infty} e^{R(t)-R(s)} \Pi_{1} d s=\eta \\
\Rightarrow e^{R(t)} \Pi_{1} \int_{t}^{\infty} e^{-R(s)} d s=\eta
\end{gathered}
$$

If we pose that: 


$$
\begin{aligned}
& f(t)=\int_{t}^{\infty} e^{-R(s)} d s \\
& \Rightarrow f(t)=-e^{-R(t)}
\end{aligned}
$$

So (b) implies that:

$$
e^{R(t)} \Pi_{1} f(t)=\eta
$$

The derivative of equation (c) with respect to time gives us:

$$
\begin{gathered}
\Pi_{1} R^{\prime}(t) e^{R(t)} f(t)+\Pi_{1} e^{R(t)} f^{\prime}(t)=0 \\
\Rightarrow R^{\prime}(t) \Pi_{1} \underbrace{e^{R(t)} f(t)}_{\eta}-\Pi_{1} e^{R(t)} e^{-R(t)}=0 \\
\Rightarrow r_{1} \eta=\Pi_{1} \\
\Rightarrow r_{1}=\frac{\Pi_{1}}{\eta}
\end{gathered}
$$

Note 8. Recall that $\mathrm{v} 2$ is an increasing function of $\mathrm{N}_{2} / \mathrm{N}_{1}$.

Note 9. This is a phenomenon of conditional convergence since each economy converges to its own equilibrium.

Note 10. The presence of economies of scale describes a situation where the unit cost of production of a productor service decrease as production increases. Economies of scale can be achieved in multiple ways. It may include the amortization of fixed costs over a larger number of units of product or productivity gains due to a learning effect and a better division of labor and specialization. In our model we assumed full employment of the labor force, thus increasing L allows increasing the size of the market. To meet market needs, the company increases its production and can benefit from economies of scale. So $L n(L 2 / L 1)$ cited in the text may reflect a scale benefit gap between the North and the South countries.

Note 11. We conduct a principal component analysis for the years 2001, 2006 and 2009. For each year, we use the first principal component, which captures more than $50 \%$ of the information contained in each database. The Bartlett test of sphericity showed significant absence of sphericity of the model. Further the test of Kaiser-Meyer-Olkin (KMO) shows that the principal component analysis of the degree of openness of the system of social regulation is of great validity.

Note 12. This data is downloaded from the website http://databank.world.org

Note 13. The Nit/Nusa $t$ variable, is endogenous because it is explained by an endogenous variable (governance) in equation (20).

Note 14. For example, Hall and Jones(1999) use the index of ethno-linguistic division. In fact, ethnic conflicts are an important determinant of economic activity in a country because they lead to political instability and poor institutional quality. The latitude of the country (latitude), which indicates the distance from the equator, has also been used as an instrument for institutional quality by Halland Jones (1999). The geographical features of a country influence the formation of sustainable institutions (Acemogluet al., 2001), which themselves affect the current scope of governance.

Note 15. This result is maintained for the fixed effects model or random effects.

Note 16. If we have one instrument per endogenous explanatory variable, there is just identification.We can't test this hypothesis. If the number of instruments exceeds the number of endogenous variables, it is called over-identification of the model. We test whether certain instruments are uncorrelated with the error term; it is the test of over-identifying restrictions or validity of the instruments.

\section{Copyrights}

Copyright for this article is retained by the author(s), with first publication rights granted to the journal.

This is an open-access article distributed under the terms and conditions of the Creative Commons Attribution license (http://creativecommons.org/licenses/by/3.0/). 